\title{
LA RESPONSABILIDAD CIVIL EN LOS PRONUNCIAMIENTOS del Tribunal Supremo de España: Aproximación al PAPEL DE LA TEORÍA DE LA IMPUTACIÓN OBJETIVA EN LA ATRIBUCIÓN CAUSAL
}

[Torts in sentences of the Supreme Court of Spain: Approach to the role of objective imputation theory on causal grounds]

\section{Franco ANDRÉs MELCHIORI*}

\section{RESUMEN}

La Sala Primera del Tribunal Supremo de España entiende que la determinación del nexo causal es un presupuesto necesario para la atribución de responsabilidad. No obstante, establecer la relación causal entre una acción y el daño ha sido siempre complejo. Por ello, buscando la solución más justa, ha deambulado de una postura a otra a lo largo de los años. Podría decirse que dicha Sala ha terminado por adoptar una postura propia que toma criterios de la teoría de la causalidad adecuada y de la teoría de la imputación objetiva. El trabajo presenta tal situación y brinda algunas luces para comprenderla mejor.

\section{Palabras clave}

Responsabilidad civil, causalidad, Tribunal Supremo de España, causalidad adecuada, imputación objetiva.

\section{ABSTRACT}

The First Chamber of the Supreme Court of Spain held that determination of causation is a necessity for the attribution of responsibility. However, the causal relationship between an action and the damage has always been complex. In its search for the best solution, the Chamber has over the years experienced a pendular movement from one position to another. It could be said that this Chamber has finally taken a sui generis position by adopting some criteria of the theory of adequate causation and the theory of objetive imputation. This paper presents such a situation and provides some lights to understand it.

\section{KeYwords}

Liability, causality, Supreme Court of Spain, adequate causation, proximate causation.

RECiBIDO el 25 de mayo y APROBADO el 1 de diciembre de 2016

* Doctor en Derecho y Ciencias Sociales por la Universidad Nacional de Córdoba (Argentina). Actualmente cursa estudios en la Universidad de Navarra. Dir.: Calle Aoiz, 2, CP: 31004, Pamplona (Navarra), España. Mail: famelchiorit@gmail.com 


\section{INTRODUCCIÓN}

La exigencia de un nexo causal entre la acción -omisión o, incluso, situación jurídica- de un sujeto y el daño como presupuesto para la existencia de responsabilidad ha desvelado a los juristas de todos los tiempos. Discrepancias, confusiones e injusticias han marcado la historia de dicho presupuesto.

El Tribunal Supremo de España (TS) no ha sido una excepción al respecto. Tanto la Sala Primera (Sala Civil) como la Sala Segunda (Sala Penal) han fluctuado de una teoría a otra, de un criterio a otro; lo ha hecho siempre en busca de la solución más justa, aunque no siempre llegó a ella.

En el presente trabajo se realizará un estudio de la postura que nace de los pronunciamientos de la Sala Civil del Tribunal Supremo a los fines de dar luces sobre la posible concepción jurídico-causal que sostiene. No se pretende, sin embargo, dar un marco completo y omnicomprensivo de toda la postura causal de la Sala Civil, ni ser una explicación detallada de cada uno de los criterios que han aparecido en sus sentencias. La pretensión es dar, según las limitaciones de un trabajo como el presente, ideas generales sobre el papel que juega en su teoría causal la teoría de la imputación objetiva según ha sido presentada por los juristas alemanes que la han extendido por el mundo (Roxin y Jakobs).

Para ello, el apartado segundo se efectuará una síntesis aproximativa de la causalidad adecuada y de la teoría de la imputación objetiva, a los solos fines de ubicar al lector en los orígenes y en la visión más generalizada sobre estas.

El tercer apartado estará dedicado a dar una visión general sobre el tratamiento que ha hecho el Tribunal Supremo de la causalidad. Aunque se haga especial referencia a la Sala Civil, se analizarán también algunas sentencias de la Sala Penal por la influencia que han tenido sobre aquella. Se analizará especialmente el trabajo de Antonio Xiol Ríos, quien integrara dicha Sala al momento de publicarlo, y se lo contrastará con pronunciamientos del TS.

El cuarto apartado se buscará dar con la concepción de causalidad adecuada que posee el TS, pues ha sido tomada por el tribunal de diverso modo a lo largo del tiempo. Se pretende aquí llegar a una idea sobre lo que es la "adecuación de la causa" como criterio jurídico de causalidad y efectuar algunas precisiones terminológicas.

El sexto apartado se dedicará a un clarificar el uso que la Sala Civil hace de la "doctrina de la imputación objetiva", retomando algunas de las conclusiones a las que se ha llegado en los apartados anteriores y pro- 
fundizando sintéticamente en los criterios propios de esta teoría que ha incorporado la Sala Civil.

Finalmente, se expondrán una serie de conclusiones breves sobre los tres apartados centrales.

\section{LA CAUSALIDAD ADECUADA Y LA IMPUTACIÓN OBJETIVA. SíNTESIS APROXIMATIVA}

La teoría de la causalidad adecuada, expuesta en el último tercio del siglo XIX y de gran aceptación entre los juristas de la actualidad, es atribuida a Luis von Bar, quien la esbozó en 1871, aunque fuera luego fundamentada por el fisiólogo Von Kries ${ }^{1}$. De una primera postura se ha ramificado una extensa lista de posiciones y se ha extendido por muchos lugares del mundo; aquí sólo se expondrá la posición inicial y la seguida por la mayoría de los civilistas contemporáneos.

En términos generales, la doctrina afirma que es adecuada la causa que más previsiblemente genera el resultado. Esa posibilidad y previsibilidad se determinan por la experiencia, considerando lo que normalmente acaece -id quod plerumque accedit-según la experiencia diaria. No requiere, pues, absoluta certeza ${ }^{2}$, pero sí cierta regularidad en el acaecer: el conocimiento es experiencial y requiere que habitualmente a tal acto le sobrevenga cual consecuencia.

Así, por esa regularidad, se llega al concepto de adaptación o adecua-

${ }^{1}$ Cfr. Goldenberg, Isidoro, La relación de causalidad en la responsabilidad civil (Buenos Aires, Editorial Astrea, 1984), pp. 33-34; Reglero Campos, Luis Fernando - Medina Alcoz, Luis, El nexo causal. La pérdida de oportunidad. Las causas de eximición de responsabilidad: culpa de la víctima y fuerza mayor, en REGLERO CAMPOS, Luis Fernando y Busto Lago, José Manuel (eds.), Tratado de responsabilidad civil, (5 $5^{\mathrm{a}}$ ed., Navarra, Aranzadi, 2014), I, pp. 782-783; Trigo RePresas, Félix, Los presupuestos de la responsabilidad civil, en Responsabilidad Civil y Seguros (2004), p. 249. No obstante, Mazeaud, Henri, Mazeaud, León y Mazeaud, Jean, Lecciones de derecho civil (Buenos Aires, Ediciones Jurídicas Europa-América, 1978), II-I, pp. 313-314, atribuye, tal doctrina directamente a Von Kries. JimÉneZ de AsúA, Luis, Tratado de derecho penal (Buenos Aires, Losada, 1951), III, pp. 455-457, hace un estudio pormenorizado de las fuentes y de los posibles iniciadores de la teoría y coincide en que quien primero se avocó a desarrollar el fundamento de la postura fue von Kries; no obstante, atribuye su origen no sólo a von Bar, sino también al prestigioso civilista Ernst Zitelmann.

${ }^{2}$ Este criterio de lo que acaece según la «experiencia diaria» o la «experiencia de la vida» es uno de entre tantos otros posibles, pero, como se explicó, aquí se sigue la teoría que tuvo mayor llegada en la doctrina y jurisprudencia civilista, pues otros autores propinaron criterios fundados en la ciencia empírica (cfr. JiMÉNEZ DE AsúA, Luis, n. (1), III, pp. 457-462). 
ción. Éste hace referencia a que el resultado de la acción debe "ajustarse" a lo esperable para esa acción del sujeto, según el curso normal de los acontecimientos. El proceso mental por el cual se analiza si una conducta es o no apta para realizar el resultado es llamado "juicio de idoneidad".

Para analizar la adaptación de la conducta (juicio de idoneidad) es necesario efectuar una determinación ex post facto de la previsibilidad del acaecimiento del resultado en razón de las condiciones precedentes. A ese "mirar hacia atrás" para evaluar la adaptación se lo llama prognosis póstuma o retrospectiva; algunos autores sintetizan el concepto con esta frase: realizar un "análisis prospectivo-retrospectivo causal"3, o "pronóstico objetivo ulterior" ${ }^{4}$ y otros diciendo que es un "juicio retrospectivo de probabilidad" , de previsibilidad.

Para algunos autores, probabilidad y previsibilidad son dos conceptos que suelen complementarse o incluso que suelen ser usados indistintamente como sinónimos. Sin embargo, para la teoría dela causalidad adecuada, lo realmente importante es la previsibilidad. Otros prefieren analizar los hechos desde una perspectiva más objetiva, científica, y sustituyen el concepto de previsibilidad por el de probabilidad: la causa adecuada es aquella que más probablemente genera el resultado.

El juicio de idoneidad es para unos "general "o "abstracto" y al realizarlo se debe analizar "[si] la acción u omisión del presunto agente era por sí misma apta para provocar el daño según el curso ordinario de las cosas; si se contesta afirmativamente... será objetivamente imputable al agente"6. Pero para otros resulta muy dificultoso "despegarse" de un análisis subjetivo de la cuestión, entre ellos se encuentra el Tribunal Supremo de España, por la influencia de su legislación.

Hasta aquí las líneas rectoras de la teoría de la causalidad adecuada que interesan para el presente trabajo. Corresponde dedicarse ahora a la teoría de la imputación objetiva.

La palabra imputación aplicada con la extensión que se le ha dado en esta teoría (como atribución) se remonta al comienzo de la segunda mitad del siglo XVII y proviene del filósofo iusnaturalista Pufendorf ${ }^{7}$. No tuvo especial acogida en la dogmática jurídica hasta que Hegel retomó el

${ }^{3}$ López Meza, Marcelo, El mito de la causalidad adecuada, en La Ley (28/2/2008), p. 2.

${ }^{4}$ Larenz, Karl, Derecho de obligaciones (Madrid, Revista de Derecho Privado, 1958), p. 200.

5 Goldenberg, Isidoro, cit. (n. 1), pp. 35.

6 Trigo Represas, Félix, cit. (n. 1), pp. 250-251.

7 Mir Puig, Santiago, Significado y alcance de la imputación penal, en Revista Electrónica de Ciencia Penal y Criminología 05-05 (2003), pp. 05-1 a 05-2. 
término y lo desarrolló como algo superador de la relación de necesidad externa y casualidad que existe en la naturaleza; lo desarrolla como un reconocimiento por parte del derecho de la persona como sujeto y espíritu cuya actuación es consecuencia de una voluntad libremente dirigida hacia la consecución de un fin ${ }^{8}$.

Con posterioridad, el concepto de imputación es desarrollado con mayor precisión por el civilista hegeliano Larenz $(1927)^{9}$ y por los penalistas Honig y Engisch (hacia los años 1930). Luego de ellos debe destacarse un aporte a esta postura efectuado por Welzel en 1939 y la de varios partidarios de la teoría de la doctrina objetivo-final de acción alrededor de las décadas de 1950 y $1960^{10}$.

Es Claus Roxin quien, en 1970, al desarrollar la doctrina del "riesgo jurídicamente relevante" permite la extensión de esta doctrina por los partidarios del funcionalismo penal y por la jurisprudencia alemana ${ }^{11}$.

En la actualidad, debe hacerse referencia también al profesor de la universidad de Bonn Günther Jakobs, pues los aportes de la teoría de roles han respondido a ciertas críticas que se hicieron a la doctrina primigenia y permitieron una mayor expansión de la doctrina ${ }^{12}$.

Quienes comulgan con la "imputación objetiva" critican las doctrinas causalistas de la dogmática penal. Afirman que el delito no puede construirse sólo con bases "naturalistas". Por eso, se aproximan al hecho desde un plano normativo ${ }^{13}$, esta crítica ha sido acogida por en numerosos países, uno de los cuales es España, tal como se verá en el apartado siguiente.

${ }^{8}$ Cfr. Rojas Aguirre, Luis, Lo subjetivo en el juicio de imputación objetiva: ¿Aporía teórica?, en Revista de Derecho (Universidad Austral de Chile) XXIII (2010), pp. 235-236.

9 LarenZ, cit. (n. 4) pp. 197-203, lo elabora dentro de la teoría de la causalidad adecuada que, sostiene, no es una teoría de la causalidad sino de la imputación.

${ }^{10}$ Cfr. Fierro, Guillermo Julio, Causalidad e imputación: caso fortuito, imputación objetiva, tentativa, delito de omisión, culposos y preterintencionales, causalidad cientifica, delito imposible (Buenos Aires, Astrea, 2002), pp. 277-279.

${ }^{11}$ Cfr. Zaffaroni, Eugenio Raúl, Tratado de Derecho Penal. Parte general (Buenos Aires, Ediar, 1981), III, p. 287; Rojas Aguirre, Luis, cit. (n. 8), pp. 241-243.

12 SALVADOR CODERCH, Pablo y FERNÁNDEZ CRENDE, Antonio, Causalidad y responsabilidad. Tercera edición, InDret 1 (2006), p. 8.

13 Zaffaroni, Eugenio Raúl - Alagia, Alejandro - Slokar, Alejandro, Derecho penal: parte general ( $2^{\mathrm{a}}$ ed., Buenos Aires, Ediar, 2005), p. 386. 


\section{Primera aproximación a la postura causal de la Sala Primera del Tribunal Supremo: Causa material y CaUsa} JURÍDICA, CAUSALIDAD ADECUADA E IMPUTACIÓN OBJETIVA

Como primera idea, debe decirse que el Tribunal Supremo (TS) ha dejado clara la exigencia de la determinación del nexo causal como requisito para la imputación de responsabilidad. También ha dejado claro que su prueba incumbe siempre el actor, a lo menos en los extremos necesarios para establecer una presunción ${ }^{14}$.

Ahora bien, ¿cómo debe resolverse el tramo de la causalidad como requisito indispensable para la existencia de responsabilidad? El TS no está exento de la general falta de criterios claros en lo tocante a la causalidad como presupuesto de la responsabilidad. En realidad, lo que en general ha sucedido es que ha fluctuado de una teoría a otra, usando conceptos de una manera y luego de otra, determinando prioridades en algunos fallos que luego son diferentes en otros, etc.

Esto parece haber ocurrido a todas las Salas del TS desde siempre. Jiménez de Asúa, en referencia a los pronunciamientos de la Sala en lo Penal de la primera mitad el siglo XX, llegó a decir que el Tribunal Supremo de España "jamás ha tenido conciencia de lo que significa el problema causal" 15 .

¿Cuáles son las causas de la falta de un criterio claro? La ausencia de una teoría uniforme en los pronunciamientos del TS responde a dos razones. La primera y principal es que, según ha sostenido desde la primera mitad

${ }^{14}$ La sentencia del 19 de febrero de 2009 podría ejemplificar lo dicho: "Constituye doctrina de esta Sala que para la imputación de la responsabilidad, cualquiera que sea el criterio que se utilice (subjetivo u objetivo), es requisito indispensable la determinación del nexo causal entre la conducta del agente y la producción del daño (SSTS 11 febrero 1998; 3 de junio de 2000; 19 octubre 2007) [...] añadiendo que "la prueba del nexo causal (...) incumbe al actor, el cual debe acreditar la realidad del hecho imputable al demandado del que se hace surgir la obligación de reparar el daño causado (SSTS 14 de febrero 1994; 3 de junio 2000, entre otras muchas)" (Tribunal Supremo de España, Sección 1a, Sala de lo Civil, de 19/2/2009, Sentencia del Tribunal Supremo, 461/2009). En adelante no se citará la Sección, siempre serán de la Sección $1^{\text {a }}$, sólo se especificará la Sala cuando sea diferente a la Sala Civil, y Sentencia del Tribunal Supremo será abreviado STS.

15 Para JiméNeZ DE AsúA, L., cit. (n. 1), pp. 554-564, por la extensión de las resoluciones, el tribunal seguía aparentemente la doctrina de la equivalencia de las condiciones con algunos "correctivos" en el plano de la culpabilidad. Afirmaba, también, que muchas veces sus resoluciones eran confusas porque parecía acercarse a la postura de la causalidad adecuada e, incluso, de la causalidad eficiente. 
del siglo XX, no debe atarse a una teoría única de causalidad, sino que debe seguir un análisis caso por caso para saber qué decisión debe tomar en ellos:

"La verdad es, y así lo tiene declarado este Tribunal en su sentencia de 25 de enero de 1933, que para establecer la relación de causalidad, más que de tesis abstractas más o menos convincentes, hay que partir de la singularidad de cada caso y del juego combinado de cuantos factores pueden ligar la ilicitud de la conducta con el resultado producido" ${ }^{16}$.

La otra razón es porque, en materia civil, el TS fue generando sus posturas de responsabilidad en torno al artículo 1902 del Código Civil español, de marcada orientación subjetivista. El texto es: "El que por acción u omisión causa daño a otro, interviniendo culpa o negligencia, está obligado a reparar el daño causado." El requisito subjetivo, claramente exigido en el artículo, es una de las razones por las que el Tribunal Supremo se ha visto obligado a mezclar los diferentes momentos de la imputación (objetiva y subjetiva) en el requisito de causalidad. Tal tendencia al subjetivismo se ve sobre todo en la aplicación de la causalidad adecuada y la exigencia de la previsibilidad.

Una postura o doctrina que podría afirmarse como uniforme, expuesta de manera más explícita a partir de las últimas décadas del siglo pasado por la Sala Segunda, es que debe diferenciarse la causa fisica o material de la causa jurídica. Podría decirse, que hoy en día es la postura seguida en los pronunciamientos del Tribunal, tanto de la Sala Segunda como de la Sala Primera ${ }^{17}$.

A medida que pasaron los años, el TS, posiblemente influenciado por la jurisprudencia de la Sala Segunda ${ }^{18}$ y por la doctrina civilista, fue adoptando la distinción mencionada en el párrafo anterior. Ello importó nombrar al tramo jurídico de la causalidad de diversas maneras: algunas veces "causalidad jurídica" (como puede verse en algunos fallos ya citados), y otras simplemente "imputación objetiva" (sin más especificaciones).

A pesar de su antigüedad en la Sala Segunda ${ }^{19}$, al menos hasta princi-

16 Tribunal Supremo de España, de 21/1/1957, STS 188/1957.

17 Algunos pronunciamientos en este sentido de la Sala de lo Civil pueden ser: de $27 / 2 / 2012$, STS $1578 / 2012$; de $6 / 2 / 2012$, STS $1581 / 2012$; de $31 / 1 / 2012$, STS 274/2012; de 20/12/2011, STS 9152/2011; del 15/12/2010, STS 7726/2010; entre muchos otros.

${ }^{18}$ Ya desde los primeros años de la década de los '80 ha incorporado en sus decisiones la terminología tomada de la doctrina y jurisprudencia alemana. Sin embargo, la Sala Segunda no tomó la doctrina alemana según la expusieron los autores más destacados, sino que en el concepto de "imputación objetiva" incluyó la idea de la causalidad adecuada. Tribunal Supremo, Sala Penal, de 20/5/1981, STS 4507/1981.

${ }^{19}$ Es ilustrativa la sentencia de 5 de abril de 1983 que, citando una sentencia de 20 de mayo de 1981, afirma que existe una diferencia entre relación causal e impu- 
pios del siglo XXI no había sido incorporada en la Sala Primera ${ }^{20}$ de modo explícito y estable. El primer pronunciamiento que hace la distinción con cierta claridad es uno de 30 de junio de 2000 y resuelve la demanda iniciada contra Repsol Butano SA y Mapegas SA por la explosión de una bombona de butano ${ }^{21}$. No obstante, las sentencias de 22 de julio $^{22}$ y 13 de diciembre de $2002^{23}$ son más explícitas en lo que hace al papel de la imputación objetiva en la determinación causal; pero la sentencia más clara y explícita al respecto es la de 30 de junio de $2009^{24}$. A los fines de mostrar la continuidad en esta postura, por ser más sintético y cercano en el tiempo, puede citarse el siguiente párrafo del fallo de 4 de octubre de 2012:

"H a y casalidad fís ic a o material, por cuanto el daño se produjo como consecuencia de la actividad desarrollada por los demandados. Hay ta m bién causalidad jurídica pues las consecuencias de la mediación e r a n p r e v i s i b l e s, como así se puso de manifiesto en las actuaciones seguidas entre la actora y la propiedad de la casa, mientras que e l juicio de reproche subjetivo recae sobre los representantes de la Inmobiliaria Centro, pues ambos incurrieron en una actividad negligente con respecto al actora" ${ }^{25}$.

tación objetiva, como categorías independientes y sucesivas (Tribunal Supremo de España, Sala Penal, de 5/4/1983, STS 1583/1983).

${ }^{20}$ Cfr. Reglero Campos - Medina Alcoz, cit. (n. 1), p. 786; Díez-Picazo, Luis, Derecho de daños, (1 $1^{\text {a }}$ ed Madrid: Civitas, 1999), p. 346.

${ }^{21}$ Tribunal Supremo de España, de 30/6/2000, STS 5348/2000.

${ }^{22}$ Tribunal Supremo de España, de 22/7/2002, STS 5568/2002. Nótese que el tribunal hace referencia a la causalidad jurídica como una "imputación objetiva" y además hace referencia al ámbito de protección de la norma.

23 Tribunal Supremo de España, de 13/12/2002, STS 8399/2002.

${ }^{24}$ Tribunal Supremo de España, de 30/6/2009, STS 4450/2009: “Así, por ejemplo (...) se debe distinguir entre 'la causalidad material o física, primera secuencia causal para cuya estimación es suficiente la aplicación de la doctrina de la equivalencia de condiciones, para la que causa es el conjunto de condiciones empíricas antecedentes que proporcionan la explicación, conforme con las leyes de la experiencia científica, de que el resultado haya sucedido', de 'la causalidad jurídica, en cuya virtud cabe atribuir jurídicamente -imputar- a una persona un resultado dañoso como consecuencia de la conducta observada por la misma, sin perjuicio, en su caso, de la valoración de la culpabilidad -juicio de reproche subjetivo- para poder apreciar la responsabilidad civil, que en el caso pertenece al campo extracontractual'. Concluye este Tribunal que, para 'sentar la existencia de la causalidad jurídica, que visualizamos como segunda secuencia configuradora de la relación de causalidad, tiene carácter decisivo la ponderación del conjunto de circunstancias que integran el supuesto fáctico y que son de interés en dicha perspectiva del nexo causal'".

25 Tribunal Supremo de España, de 4/10/2012, STS 6203/2012 Otro interesan- 
Se puede afirmar que la causa fáctica para el TS no permite la atribución de autoría a los fines de la responsabilidad civil. La postura de la "equivalencia de las condiciones" es tomada desde un punto de vista naturalístico, físico; de ella se sirve el derecho. Para la determinación de este "aspecto fáctico" se ha sugerido en algún pronunciamiento el recurso a las leyes científicas -las ciencias empíricas tienen mucho que decir al respecto-. El Tribunal parece coincidir con la siguiente afirmación de Díez-Picazo: "la llamada teoría de la equivalencia de las condiciones, proporciona un concepto que se encuentra manifiestamente basado en el molde de las ciencias naturales y que es por ello muy del gusto de la vieja escuela positivista, pero que no tiene en cuenta las finalidades específicas del Derecho en general y del instituto de la responsabilidad civil en particular, por lo que no es de extrañar que pueda conducir a resultados prácticos que, prima facie, hay que rechazar" ${ }^{\prime 2}$.

Finalmente, cabe decir que la distinción entre el tramo fáctico de la relación causal y el tramo jurídico de la imputación no se ha debido ú n i c a me n te a una postura filosófico-jurídica. Se debe también a un motivo muy concreto de orden procesal: el TS no atiende cuestiones fácticas, sino jurídicas. Teniendo la causalidad un tramo imputativo que es de corte netamente jurídico, la Sala Civil del TS podría así resolver cuestiones de causalidad.

Corresponde ahora dedicarse a aquel tramo de la imputación jurídica de la causa. El TS no ha sido claramente uniforme en la determinación de esa "causalidad jurídica"; en sus pronunciamientos ha recurrido a lo largo de estas últimas décadas a diversas teorías y criterios.

En la Sala Civil prevaleció como único criterio jurídico durante unos años la teoría de la causalidad adecuada. Luego de una aproximación paulatina, diferenciando primero entre condiciones y haciendo referencias a la previsibilidad, terminó por citarla de manera expresa. Sin embargo, a medida que fue pasando el tiempo, la causalidad adecuada tomó diferentes matices y funciones jurídicas.

Debe considerarse que mientras la explicitación de la distinción entre causalidad fáctica e imputación jurídica es relativamente reciente, el recurso a la teoría de la causalidad adecuada tiene algunos lustros más. Por ello, antes de la distinción entre el tramo fáctico y el jurídico, algunos juristas pusieron de resalto que la teoría de la causalidad adecuada era una teoría de la imputación y exigieron de los tribunales mayor claridad en el asunto ${ }^{27}$.

te pronunciamiento al respecto es el de 15/12/2010 (STS 7726/2010).

${ }^{26}$ Díez-Picazo, cit. (n. 20), pp. 334-335. El autor hace suya la frase de João de Matos Antunes Valera, al cual no se ha tenido acceso.

${ }^{27}$ Parece haber sido precursor en esta exigencia ibid., pp. 336 y 340 ; en el mismo 
Más o menos paralelamente se comienzan a tener en cuenta, sin dejar de lado los criterios de la causalidad adecuada, criterios tales como "acrecentamiento del riesgo" (para ciertos supuestos de responsabilidad y, en general, según la ley les permitía expresarse) y otros que atañen más a la llamada "teoría de la imputación objetiva". Esta última actitud pudo generar aun mayores confusiones.

No resulta fácil distinguir cuándo el TS se refiere a la "imputación objetiva" como tramo jurídico de la relación de causalidad, y cuándo se refiere a la "imputación objetiva" como una teoría de la que deben tenerse en cuenta sus criterios rectores (criterios que, como es sabido, no incluyen la "causalidad adecuada", sino que se presentan como una alternativa a esta). Tal distinción no sería importante si el TS tomara como únicos criterios de imputación jurídica causal los propios de la imputación objetiva según se han popularizado. El trabajo publicado por Juan Antonio Xiol Ríos ${ }^{28}$, quien fuera Presidente de la Sala de lo Civil del TS y actualmente integra el Tribunal Constitucional, es un trabajo que no podría dejar de analizarse, pues, a nuestro entender, lo que afirma no se corresponde totalmente con las decisiones que, caso a caso, ha tomado el Tribunal.

El autor afirma que el TS utiliza la imputación objetiva de diferentes maneras. Como "técnica positiva" para atribuir responsabilidad a la Administración, como "técnica de reducción del nexo de causalidad", como "técnica de integración del nexo de causalidad" y como "técnica de integración de la responsabilidad".

En lo que a causalidad se refiere, el Magistrado dijo que "la doctrina de la imputación objetiva tiene como antecedente la teoría de la causalidad adecuada" ${ }^{29}$. Y luego afirma que la doctrina de la imputación objetiva cumple un papel "limitativo" de la causalidad fáctica, utilizando para ello los siguientes "criterios": "(a) criterio de la causalidad adecuada o eficiente, que incluye la falta de proximidad al resultado dañoso de la conducta del agente, falta de control por parte del agente, la intervención de terceros, la ausencia de incremento del riesgo por parte del agente, la ausencia de creación por éste de una situación de confianza, como ocurre cuando se erige en garante del cumplimiento de una obligación; y, con carácter contrapuesto, la asunción del riesgo por el perjudicado, el consentimiento por la víctima de la causa del daño, el deber de asumir los riesgos generales

sentido, Reglero Campos, - Medina Alcoz, cit. (n. 1), p. 783; Fernández Crende, Antonio, «Imputación objetiva en un caso de responsabilidad civil ex delicto: criterio de la provocación Comentario a la STS 2a 26.9.2005», InDret 1/2006, p. 5.

${ }^{28}$ Cfr. Xiol Ríos, José Antonio, «La imputación objetiva en la jurisprudencia reciente del Tribunal Supremo", La Ley - Actualidad Civil 2 (2010), p. 123.

${ }^{29}$ Ibid. 
de la vida, y la relevancia de la intervención de la propia víctima cuando le corresponde el control de la situación o el deber de mitigar el daño; (b) criterio de la prohibición de regreso, aplicable cuando se aprecia que uno de los antecedentes del daño es una conducta de tercero que reúne unas características tales que justifica eliminar la imputabilidad causal de las anteriores impidiendo el retroceso en la cadena causal; (c) criterio del ámbito de protección de la norma infringida" 30 .

Asiste razón a Xiol Ríos en cuanto afirma que el TS utiliza la "causalidad adecuada" como uno de los criterios de la imputación objetiva del resultado, en conjunto, claro está, con otros criterios (preponderantemente de la teoría de la imputación objetiva según la doctrina alemana) ${ }^{31}$.

Aunque Xiol Ríos dé este orden a los criterios, no pare ser el que sigue el TS. En efecto, tribunal muchas veces utiliza el criterio de la causalidad adecuada como c lá u s u la de c i e r r e. ¿Sería entonces antecedente de la doctrina de la imputación objetiva, criterio de aplicación dentro de esta y, todo a la vez, cláusula de cierre? Parece ser que la Sala Segunda considera que no se debe buscar una incompatibilidad entre todas estas posibilidades, y aplicar al caso concreto lo que convenga a la justicia, sin preocuparse de disquisiciones "teóricas".

El actual Magistrado del Tribunal Constitucional dice primero que la teoría de la causalidad adecuada e $s$ u n a n te ce d e n t e de la doctrina de la imputación objetiva; y ello es así, según puede verse en los pronunciamientos de la Sala Civil. Luego sostiene que la imputación objetiva se realiza según unos criterios, dentro de los cuales uno implica recurrir a la teoría de la causalidad adecuada (o eficiente) ${ }^{32}$. Ello también es asín ${ }^{33}$.

Lo "novedoso" es el contenido que le da Xiol Ríos a ese primer criterio. Lo componen diferentes subcriterios, algunos de los cuales relacionan el resultado con la acción del agente, y otros con la de la víctima. Entre los primeros, menciona "la falta de proximidad al resultado dañoso de la conducta del agente", criterio éste que utilizaba la llamada teoría de la causa próxima, muy diverso a los criterios a los que recurre la que actualmente

30 Ibid.

31 Véase, por ejemplo el fallo de 20 de diciembre de 2007: "se ha de efectuar, pues, el posterior juicio de imputación para llegar a establecer la causalidad jurídica, que consiste en una valoración de las diversas conductas concurrentes y de sus respectivas circunstancias, al objeto de determinar si puede ponerse a cargo del agente el daño producido, o en qué medida es justo hacerlo, lo que depende de una serie de criterios de imputación objetiva, entre los cuales se encuentra el de la causalidad adecuada" (Tribunal Supremo de España, de 20/12/2007, STS 8265/2007).

${ }^{32}$ Cfr. Xiol Ríos, cit. (n. 28), p. 127.

${ }^{33}$ Véase, por ejemplo, el fallo del Tribunal Supremo de España, de 15/12/2010, STS 7726/2010. 
es llamada teoría de la causalidad adecuada. No obstante, sí es cierto que muchas veces la proximidad de la conducta con el resultado da luces sobre su posible relación de causa-efecto.

Después menciona la "falta de control por parte del agente", que es un criterio más propio de la teoría de la imputación objetiva: el control del riesgo creado por parte del agente; que es lo mismo que decir: control de la acción, ya que para la teoría de la imputación objetiva, lo que los sujetos "administran" con sus acciones es el riesgo. También es mencionada "la intervención de terceros", que es un criterio que interrumpe el nexo causal o lo desvía, ligado a la idea de adecuación, pero no exclusivo de ella. Es un criterio utilizado para la interrupción del nexo causal también en la teoría de la causalidad adecuada: la conducta del tercero impediría llamar "adecuada" a la acción del agente primigenio.

Menciona, además, "la ausencia de incremento del riesgo por parte del agente", otro criterio de la teoría de la imputación objetiva y no de la teoría de la causalidad adecuada, que no conocía realmente el criterio del riesgo creado. Termina los subcriterios en relación al agente mencionando "la ausencia de creación por éste de una situación de confianza, como ocurre cuando se erige en garante del cumplimiento de una obligación”, criterio de la teoría de la imputación objetiva.

En relación a la conducta de la víctima alude a "la asunción del riesgo por el perjudicado", "el consentimiento por la víctima de la causa del daño", "el deber de asumir los riesgos generales de la vida", y "la relevancia de la intervención de la propia víctima cuando le corresponde el control de la situación o el deber de mitigar el daño". Todos ellos así descritos hacen pensar en la teoría de la imputación objetiva (aunque no son exclusivos de esta), siendo el anverso o reverso de sus criterios.

Resulta al menos curiosa la elasticidad del concepto de adecuación que propone Xiol Ríos, una elasticidad que en cierto sentido se aparta de la tradición jurídica sobre la adecuación de la causa; la carga de un contenido que se encuentra más "cómodo" en otro ámbito: aquel en el que la idea de riesgo creado es el eje del sistema, cosa que no acaece en España.

Tal elasticidad contrasta con algún pronunciamiento de la Sala Segunda, que pretende atribuir a la "adecuación de la causa" el contenido propio de la teoría de la causalidad adecuada. Así lo afirmó en una sentencia de 17 de abril de 2007: "Ocurre, sin embargo, que muchas veces se cruzan ambas operaciones (la fijación de la relación de causalidad y la determinación de la imputación objetiva), pues se utiliza como criterio de imputación la denominada teoría [...] de causalidad adecuada, que contiene elementos fácticos y jurídicos y viene a expresar que el evento es una consecuencia que razonable y generalmente cabe conectar a la conducta del agente, 
sin concurrencia de elementos que permitieran descartar o denegar la imputación"34.

\section{SigNIFICADO Y FUNCIÓN DE LA "CAUSALIDAD ADECUADA" para el Tribunal Supremo}

Luego del análisis anterior, es menester abocarse a la consideración de si la causalidad adecuada es para el TS "un criterio" de rico contenido que actúa en un primer momento (en la descripción de Xiol Ríos sería el criterio a), comofiltro de los restan te $s$; o, quizás, como una cláusula de cierre; es decir, que actúa al final, cuando los demás criterios "han fallado".

El autor que ahora se comenta refiere a un "criterio de adecuación" también como cláusula de cierre (lo había mencionado como el primero y principal): "El criterio de la adecuación, aparece en último lugar en la escala de preferencias, pues ya se ha visto cómo es considerado por el TS como una cláusula de cierre" 35 . Al mencionar casos concretos en los que se aplica como clá usula de ci e r r e trae a colación algunos de los descritos anteriormente: la relevancia de la intervención de la propia víctima cuando le corresponde el control de la situación ${ }^{36} \mathrm{o}$ la posición de garante ${ }^{37}$.

La afirmación dada sobre que el criterio de la causalidad adecuada "se encuentra en el último lugar de la escala de preferencias", puede encontrar su fundamento en algunos pronunciamientos del órgano jurisdiccional. Ya que algunas veces lo aplica simplemente en último lugar; otras, como en el siguiente párrafo de un fallo de 21 de octubre de 2005, lo aplica en último lugar y además aclara que el criterio puede ser usado como cláusula de cierre: "Evidentemente hay causalidad física o material -«questio facti» para la casación- (...) Pero no hay causalidad jurídica-juicio perteneciente a la «questio iuris»-, bien porque se entienda aplicable la exclusión en virtud del criterio de imputación objetiva del «riesgo general de la vida», bien porque no ha sido la intervención la denominada causa próxima o inmediata, ni la causa adecuada, criterio éste (para unos, filtro de los restantes criterios de imputación; para otros, residual de cierredel sistema, y que, por ende, ope-

34 Tribunal Supremo de España, de 17/4/2007, STS 2561/2007. Nótese que para este pronunciamiento la causalidad adecuada no es un criterio puro de imputación, sino un criterio que es en parte fáctico y en parte normativo.

35 Xiol Ríos, cit. (n. 28), p. 134.

36 Tribunal Supremo de España, de 24/10/2003, STS 6556/2003.

37 Tribunal Supremo de España, de 24/11/2008, STS 6277/2008. 
ra cuando no sea aplicable alguno de los previstos específicamente en la doctrina-riesgo general de la vida, provocación, prohibición de regreso, incremento del riesgo, ámbito de protección de la norma, consentimiento de la víctima y asunción del propio riesgo, y de la confianza-) que descarta la causalidad cuando, como dice la doctrina, «el daño aparece como extraordinariamente improbable para un observador experimentado que contara con los especiales conocimientos del autor y hubiese enjuiciado la cuestión en el momento inmediatamente anterior a la conducta»" 38 .

Resulta interesante remarcar que la frase resaltada en cursiva responde a la diversidad de criterios que existe dentro del mismo tribunal. Como bien dice el fallo anterior, en algunos pronunciamientos la causalidad adecuada parece ser el criterio principal o casi único dentro de la "imputación objetiva", quizás "filtro de los restantes" ${ }^{39}$.

Según lo expuesto hasta aquí, aparentemente el TS sigue una doctrina similar a la que expone F. Pantaleón en su aporte al trabajo colectivo realizado en conmemoración del centenario del Código Civil de España ${ }^{40}$. Allí, en un extenso capítulo, luego de desarrollar todos los criterios de la teoría de la imputación objetiva (trayendo a colación casos en los que parecen haberse aplicado), propone agregar a estos criterios el criterio de la adecuación (de la causalidad adecuada), pero según la postura de Tranger (que se explicará a continuación). La teoría jurídica correctora de la conditio sine qua non debe ser la de la imputación objetiva, pero, como integrante de sus criterios, debe agregarse el propuesto por la teoría de la

38 Tribunal Supremo de España, de 21/10/2005, STS 758/2005, el resaltado es propio.

39 Véase, por ejemplo Tribunal Supremo de España, de 23/4/2009, STS 2215/2009: “La Sala ha aceptado así la denominada 'imputación objetiva' en la que no se busca si uno de los elementos de la relación es la causa del resultado, sino si la conducta que se pretende sea la causa, es suficientemente relevante para la producción del daño por el que se reclama, de acuerdo con el criterio de la 'adecuación' (SSTS de 6 septiembre 2005, 10 febrero y 12 diciembre 2006, así como otras posteriores). En este caso, se cumplen los requisitos que esta Sala ha atribuido a la causalidad jurídica o imputación objetiva”.

${ }^{40}$ La propuesta es acogida positivamente también por DíEz-PiCAzo, cit. (n. 20), p. 349. El recurso a la causalidad adecuada como criterio para la imputación objetiva de la conducta no es exclusivo de España. Es más, el mismo Larenz al desarrollar el criterio de imputación objetiva lo hizo como modo de comprender lo que realmente sucede en la teoría de la causalidad adecuada. De todas formas el TS propone unir la causalidad adecuada y la teoría de la imputación objetiva según los criterios universalizados por Roxin y Jakobs. 
causalidad adecuada. Según este prestigioso jurista, no habría contradicción ni superposición alguna y la "complementariedad" sería positiva ${ }^{41}$.

Conviene ahora, simplemente, completar de forma sintética el marco conceptual. Por ello, se hará un intento de clarificar el uso que se hace de "causa eficiente" y el "contenido" que el TS da al "criterio de adecuación".

Se ha dicho que la causalidad adecuada ha tenido un lugar preponderante en los fallos del $\mathrm{TS}^{42}$, tanto cuando era tomado como teoría causal como cuando pasó a ser un criterio de imputación objetiva del resultado -independientemente del lugar que ocupe en el análisis jurídico, ha sido siempre relevante-. Sin embargo, en algunos pronunciamientos el TS menciona que la causa debe ser eficiente, o afirma que así ha sido en un caso concreto $^{43}$ (se ha visto que el mismo texto de Xiol Ríos menciona indistintamente los dos conceptos como equivalentes ${ }^{44}$ ).

Ante tal circunstancia debe decirse que la referencia de la Sala Primera a que la causa deba ser eficiente no implica que el tribunal siga la teoría de la causa eficiente ${ }^{45}$; aunque así parezca algunas veces, se entiende que hace un uso indistinto de los términos "adecuada" y "eficiente" para referirse a la misma visión de la realidad, que corresponde más con el de la causalidad adecuada. El uso indistinto genera confusión acerca de la postura que mantiene; pero se comparte al respecto la postura de dos prestigiosos juristas españoles, que sostienen:

"Como digo [sic], la fórmula empleada por la jurisprudencia de la Sala Primera del TS es enormemente confusa. Del 'maremagnum' conceptual en que está sumida cabe extraer, en lo que ahora interesa, la siguiente doctrina: para la determinación de la existencia de la relación de causalidad entre la acción y omisión y el daño o perjuicio resultante es de aplicación el principio de la causalidad adecuada" ${ }^{46}$.

${ }^{41}$ Pantaleón, Fernando, "Causalidad e imputación objetiva: Criterios de imputación», en Asociación de Profesores de Derecho Civl (ed.), Centenario del Código Civil (1889-1989), (Madrid, Centro de Estudios Ramón Areces, 1990), I, pp. 1561-1591.

${ }^{42}$ Concuerdan con esta idea Reglero Campos - Medina Alcoz, cit. (n. 1), p. 782.

${ }^{43}$ Ver, por ejemplo, Tribunal Supremo de España, de 19/11/2008, STS $5993 / 2008$.

${ }^{44}$ Se ha dicho que el mismo tribunal, no sólo utiliza el término "eficiente" en lugar de "adecuada", sino que a veces parece confundirlo con el plano fáctico de la equivalencia de las condiciones. Cfr. Reglero Campos -Medina Alcoz, cit. (n. 1), pp. 785-786. Allí estos autores citan también algunas frases del fallo y ponen en duda la claridad expositiva del Tribunal Supremo.

${ }^{45}$ Cfr. ibid., p. 786.

46 Ibid. 
¿Cuál es el contenido de esa adecuación de la conducta? ¿Es aquel "rico" contenido del que habló Xiol Ríos? ¿ $\mathrm{O}$ su contenido responde a aquel que se le ha dado en muchos países desde hace más de un siglo? Podría dar luces sobre el asunto una sentencia de la Sala Primera de 1997. En este pronunciamiento resolvió el caso de una mujer que fue agredida cuando ingresó de madrugada a una sucursal bancaria para extraer dinero. La cerradura estaba rota y ello permitió que ingresara un ladrón que, luego de forcejear con la actora, la hirió con un arma blanca. El TS afirmó que para determinar la existencia de nexo causal: "la doctrina jurisprudencial vienen aplicando el principio de causalidad adecuada, que exige, para apreciar la culpa del agente, que el resultado sea una consecuencia natural, adecuada y suficiente de la determinación de la voluntad" ${ }^{37}$.

La definición que se acaba de exponer, contrasta con la definición de causalidad adecuada que en su momento propusiera F. Pantaleón, según la doctrina de Tranger. Díez-Picazo sintetiza la definición del autor alemán de la siguiente manera:

"no se puede imputar objetivamente un concreto resultado dañoso a la conducta del autor cuando la producción de este evento hubiera sido descartada como extraordinariamente improbable, por un observador experimentado, que hubiera contado con los especiales conocimientos del autor y hubiese enjuiciado la cuestión ex ante, es decir, en el momento en que el autor se dispuso a realizar la conducta que desembocó en el resultado dañoso de cuya imputación se trata" ${ }^{48}$.

Según esta visión, se requiere un juicio retrospectivo al momento de actuar el agente y un "estándar" de conocimiento ("observador experimentado, que hubiera contado con los especiales conocimientos del autor”). Tales extremos, tal como se exponen, no parecen haber sido exigidos comúnmente por la Sala Civil. Así como tampoco parece ser "tan levemente exigente" en la probabilidad de acaecimiento del hecho (el TS no exige que el hecho deba aparecer previamente como "extraordinariamente improbable" para que el agente se libere).

Aunque en apariencia la Sala Civil ha seguido la postura propuesta por F. Pantaleón en los demás componentes, no puede decirse lo mismo en cuanto al contenido que F. Pantaleón da a la causalidad adecuada. También es importante mencionar que la Sala Civil no ha dado una única definición, pero la visión más generalizada en estas últimas décadas es la que se acaba de citar $^{49}$.

47 Tribunal Supremo de España, de 1/4/1997, STS 2312/1997.

48 Díez-Picazo, cit. (n. 20), p. 348.

49 En posición coincidente puede verse Reglero Campos - Medina Alcoz, cit. (n. 1), p. 786 . 
En este marco de ideas, resta decir que lo propuesto por Xiol Ríos no es ajeno a los pronunciamientos del tribunal. Algunas veces (no parece ser así en la mayoría de los casos) el tribunal al afirma que para que exista relación causal el resultado debe ser una "consecuencia natural, adecuada y suficiente, valorada conforme a las circunstancias que el buen sentido impone en cada caso" (la definición que se ha visto antes), lo toma como sinónimo de "causa jurídica". Y para determinar si ello es así realmente, o sea para aplicar "el buen sentido", recurre a los criterios de la imputación objetiva, tal y como se han desarrollado en sede alemana ${ }^{50}$. Se toma en estos pronunciamientos "causa adecuada" como aquella que resulta de aplicar todos los criterios jurídicos, es decir, como la razón de ser de la "búsqueda" jurídica en el tramo de la imputación objetiva: la causa jurídica es la "adecuada al daño" y se determina por los criterios de imputación objetiva. Ello incluye también los criterios que Xiol Ríos ha mencionado aparte (b y c), incluye todos.

En la sentencia citada al definir causalidad adecuada la Sala Civil continúa: “...debiendo entenderse por consecuencia natural, aquella propicia, entre el acto inicial y el resultado dañoso, una relación de necesidad, conforme a los conocimientos normalmente aceptados; y debiendo valorarse en cada caso concreto, si el actor antecedente que se presenta como causa, tiene virtualidad suficiente para que del mismo se derive, como consecuencia necesaria, el efecto lesivo producido, no siendo suficiente las simples conjeturas, o la existencia de datos fácticos, que por una mera coincidencia, induzcan a pensar en una posible interrelación de esos acontecimientos, sino que es precisa la existencia de una prueba terminante relativa al nexo entre la conducta del agente y la producción del daño" ${ }^{51}$.

No es del todo feliz el uso del término "necesidad" para explicar la relación entre la acción del agente y el daño causado. La teoría de la causalidad adecuada se asienta no sobre la necesidad, sino sobre la probabilidad, es esa "probabilidad" la que genera la "previsibilidad" de acaecimiento del daño. El TS pretende, de manera pragmática, que se encuentre aquella acción que más probablemente generó el resultado; ello lo lleva a descuidar el uso de los términos.

Lo mismo cabe decir, en el ámbito de la "adecuación" de una acción al resultado, sobre el uso del término "previsibilidad" 52 . El recurso a la idea de previsibilidad puede llevar a confundir los dos tramos de la imputación (objetiva y subjetiva).

50 Tribunal Supremo de España, de 22/2/2010, STS 745/2010.

51 Tribunal Supremo de España, de 1/4/1997, STS 2312/1997.

52 Tribunal Supremo de España, de 4/10/2012, STS 6203/2012; de 11/6/2012, STS 3955/2012; de 29/4/2006, STS 2172/2006; de 7/6/2006, STS 619/2006. 
Esta “imprecisión” terminológica no es exclusiva de la Sala Civil del TS. Asiste razón a Encarna Roca Trías, en ese momento magistrada del TS, cuando dice que los criterios de previsibilidad a los que recurre la Sala Civil para imputar la causalidad son el producto de la influencia de los criterios europeos sobre responsabilidad civil extracontractual ${ }^{53}$.

Los denominados "Principios de derecho europeo de la responsabilidad civil" ${ }^{4}$, en su artículo 1:101, establecen que "La persona a quien se pueda imputar jurídicamente el daño sufrido por otra está obligada a repararlo", para luego aclarar que este daño se imputa a aquel "a) cuya conducta culposa lo haya causado; o b) cuya actividad anormalmente peligrosa lo haya causado; o c) cuyo auxiliar lo haya causado en el ejercicio de sus funciones". Finalmente el art 5:101, (2) dice que es una "actividad anormalmente peligrosa” aquella que “a) crea un riesgo previsible y significativo del daño incluso aunque se emplee todo el cuidado debido en su ejercicio y b) no es una actividad que sea objeto de uso común”.

\section{PAPEl de la teoría de la imputación ObJETIVA: APORTAR EL MARCO JURÍDICO Y CRITERIOS DE IMPUTACIÓN}

Se ha visto cómo la Sala Civil del TS llama imputación objetiva a todo el tramo imputativo causal, hace explícitos los criterios de imputación objetiva, pero adicionando el criterio de adecuación y algunas veces teñidos de ideas de adecuación y previsibilidad. Se ha propuesto como razón generadora de esa postura -que se podría llamar "mixta"- el influjo del prestigioso jurista español F. Pantaleón. Es posible que no sea del agrado de dicho jurista la situación de confusión que se ha generado, pero actualmente, como miembro de la Sala Civil del TS tiene la oportunidad de clarificar el uso de ciertos términos.

Quizás, al analizar los pronunciamientos del TS uno debe evitar acercarse con "precomprensiones dogmáticas": la “imputación objetiva” siempre será el momento de imputación jurídica de la relación causal; nunca se estaría hablando únicamente de la "teoría de la imputación objetiva" y a sus criterios, sino del momento jurídico mismo de tal imputación. Los criterios que rigen dicha imputación objetiva pueden ser nacidos en torno a la teoría de la adecuación, o nacidos en torno a la teoría de la imputación objetiva. De ser así, podría decirse que el Tribunal Supremo implementó

53 Roca Trías, Encarna, «El riesgo como criterio de imputación subjetiva del daño en la jurisprudencia del Tribunal Supremo", InDret 4 (2009), pp. 5-6.

${ }^{54}$ Disponibles al 16 de julio de 2015 en el sitio oficial del European Group on Tort Law: http://www.egtl.org/, la traducción utilizada es oficial. 
una postura para la imputación del resultado de características únicas ${ }^{55}$; eso sí, características que aún no parecen totalmente definidas ${ }^{56}$.

Puede llegarse, "cortando aquí y allá”, a una posición, quizás similar -con los “ajustes” que el lector podrá apreciar- a la propuesta por Xiol Ríos en el trabajo citado.

La imputación objetiva es el nombre que se da al tramo jurídico objetivo de la atribución causal. De este modo, la teoría funciona como marco general. Ese tramo imputativo se realiza mediante la aplicación de una serie de criterios tomados de la llamada teoría de la imputación objetiva (principalmente según la han extendido Roxin y Jakobs) y con elementos de la teoría de la causalidad adecuada (como puede verse en algunas sentencias: entremezclados, o mutuamente influenciados), que funciona también como criterio rector y propósito. En el tramo imputativo se buscaría determinar cuál es la causa adecuada al daño, y para ello se recurre a los diversos criterios antedichos. Estos criterios permiten imputar el hecho al agente o desplazar la imputación.

A diferencia de lo que parece sugerir Xiol Ríos, no existe un orden en la utilización de tales criterios; se aplica aquel que corresponde cuando se

55 El mismo Roxin, en postura que no se comparte, ha encontrado puntos de contacto entra la teoría de la imputación objetiva y la teoría de la causalidad adecuada. Véase Roxin, Claus, Derecho penal: parte general. 1, Fundamentos, la estructura de la teoría del delito (Madrid, Civitas, 2008), p. 367.

56 Véase la sentencia de 11 de junio de 2012, pues es muy ilustrativa en lo que a esto respecta (entre corchetes se expondrán comentarios haciendo referencia a las posibles teorías causales y criterios involucrados): "Los hechos que se mencionan permiten sentar las siguientes apreciaciones: a) hubo una omisión de medidas de seguridad, vigilancia y cuidado, que de haberse adoptado, con absoluta certeza, o al menos gran probabilidad, habrían podido evitar el accidente [utiliza elementos fácticos para la antijuridicidad y hace referencia a la probabilidad]. b) Hay causalidad física o material, por cuanto las lesiones se produjeron como consecuencia de la caída por la ventana. c) Hay causalidad jurídica -atribuibilidad- pues se creó el riesgo del resultado jurídicamente desaprobado [propio de la teoría de la imputación objetiva] y que era previsible dadas las características de Lina y la forma de solucionar el conflicto que se creó a partir de un estado de nerviosismo y alteración [forma de juzgar más propia de la teoría de la causalidad adecuada, la teoría de la imputación objetiva obligaría a utilizar otros términos y efectuar parcialmente este análisis en el tramo subjetivo], por lo que la falta de las medidas de seguridad aparece como causa próxima [¿teoría de la causalidad próxima o simplemente se refiere a una situación fáctica?] y adecuada para producir el daño [causalidad adecuada], y d) el juicio de reproche subjetivo recae sobre la recurrente por no haber actuado con la diligencia que el caso exigía a los monitores y responsables de ACELL" (Tribunal Supremo de España, de 11/6/2012, STS 3955/2012). 
cree que corresponde, incluso se ha aplicado más de uno para fundar un pronunciamiento $^{57}$.

El orden de aplicación de los criterios de imputación objetiva (tanto el de adecuación como los demás), no es determinante. Lo que realmente importa es que se apliquen, y que se apliquen correctamente para impartir justicia; sí es cierto que los principios rectores fundamentan, completan y articulan el uso de los demás, pero el recto uso de cada criterio presupone esa inteligencia.

Establecer un orden de prelación de los criterios de imputación que utiliza el TS sería, no obstante, útil para el resto de los operadores jurídicos. Y facilitaría aún más efectuar una breve lista de lo $s$ c r i t e r i o s m ás extendidos e n el mundo jurídico. La Sala Civildel TS lo ha hecho en algunos pronunciamientos. A la vez que invitamos a seguir en esta línea, los mencionaremos y analizaremos brevemente. Por definir un orden a los meros fines de esta exposición se ha elegido el dado por la sentencia de 21 octubre 2005: riesgo general de la vida, provocación, prohibición de regreso, incremento del riesgo, ámbito de protección de la norma, consentimiento de la víctima y asunción del propio riesgo, y de la confianza ${ }^{58}$.

Conviene comenzar por la piedra de toque del sistema: el criterio del riesgo permitido 59 (conocido también como "riesgo general de la vida"). Al decir del mismo Tribunal Supremo, "necesariamente el comportamiento humano, en la generalidad de los casos, según la regla id quod plerumque accidit [las cosas que ocurren con frecuencia] implica soportar los pequeños riesgos" 60 . Éstos son riesgos no cualificados (en contraposición a los "muy

57 Se ve tal utilización "indistinta" en el siguiente pronunciamiento: "Por consiguiente, ha habido la omisión de deber de cuidado que opera como contribución causal, y con la entidad suficiente para que la actuación del empleado no absorba en exclusiva el desencadenante causal, lo que se traduce en la exclusión de la doctrina de la prohibición de regreso que se aduce en el motivo. Y aun contemplando el caso a la luz de la doctrina de la causalidad adecuada (que sea de examen previo, o de aplicación en defecto de otra pauta, es también de imputación objetiva) no se excluye su responsabilidad —imputabilidad — porque, habida cuenta las circunstancias expuestas, no cabía descartar como extraordinariamente improbable (ex ante y por un observador experimentado, suficientemente informado) el resultado producido" (Tribunal Supremo de España, de 17/5/2007, STS 545/2007).

${ }^{58}$ Ya citada. Existe una sentencia posterior que la cita y repite los criterios mencionados en esta sentencia, pero en otro orden, claro (Tribunal Supremo de España, de 7/6/2006, STS 619/2006).

59 Cfr. Fernández Crende, cit. (n. 12), p. 5; Díez-Picazo, cit. (n. 20), pp. 343 y 346; Reglero Campos, Luis Fernando y Medina Alcoz, Luis, cit. (n. 1), pp. 788790; JAKOBS, Günther, cit. (n. 13), pp. 59-67.

${ }_{60}$ Tribunal Supremo de España, de 2/3/2006, STS 1469/2006. 
cualificados"), "pues riesgos hay en todas las actividades de la vida" ${ }^{61}$ y no se puede responsabilizar a nadie por los daños que puedan generarse por su concreción en un daño.

El criterio de provocación, afirma Fernández Crende, hace responsable "a quien haya creado ilegítimamente un peligro para alguna otra persona o sus bienes de cualesquiera daños sufridos durante la persecución para atraparle o durante el intento de proteger los bienes jurídicos puestos en peligro". Es un criterio de aplicación inusual, aunque la Sala Segunda lo ha aplicado no hace muchos años ${ }^{62}$.

El criterio de "prohibición de regreso". Excluye la imputación a un sujeto cuando en la cadena causal se interpone la acción de un tercero mediante una conducta dolosa o gravemente negligente. Sin embargo, la acción primigenia puede poseer "entidad suficiente para que la actuación del empleado [un tercero en la relación causal] no absorba en exclusiva el desencadenante causal" ${ }^{63}$.

El "incremento del riesgo" es un criterio que, junto con el riesgo general de la vida, responden más directamente al "núcleo" de la imputación objetiva en sede civil. Si la acción de un sujeto no acrecienta el riesgo de producción de un daño de modo determinante (o coadyuvante) no puede tomarse como generadora del mismo. Ha sido aplicado con cierta frecuencia por la Sala Civil del TS ${ }^{64}$.

El "ámbito de protección de la norma" podría explicarse diciendo que permite exonerar a un sujeto cuando su acción ilegítima viola una previsión jurídica que no buscaba proteger el bien jurídico lesionado. Es un criterio de poca aplicación efectiva en sede civil para la exoneración de un sujeto, aunque de mucha aplicación en sede penal. Sí se ha mencionado numerosas veces para hacer notar que la infracción concreta responde al bien jurídico que la norma pretendía proteger ${ }^{65}$.

El TS menciona como un mismo criterio "consentimiento de la víctima y asunción del propio riesgo", ya que, podría decirse, el consentimiento de la víctima implica que ella se haga cargo del riesgo de determinada actividad, lo asume personalmente. "El riesgo que esta persona crea [el agente principal] se traslada al ámbito de responsabilidad de la víctima, que controla y asume esta fuente de peligro"66. Es uno de los criterios a los que más recurre el TS.

\footnotetext{
${ }^{61}$ Tribunal Supremo de España, de 17/7/2003, STS 5108/2003.

${ }_{62}$ Tribunal Supremo de España, Sala Penal, de 26/9/2005, STS 5537/2005.

${ }^{63}$ Tribunal Supremo de España, de 17/5/2007, STS 545/2007.

${ }^{64}$ Tribunal Supremo de España, de 14/3/2008, STS 4329/2008.

${ }_{65}^{65}$ Por ejemplo, Tribunal Supremo de España, de 30/7/2008, STS 4766/2008.

${ }^{66}$ Tribunal Supremo de España, de 18/03/2014, STS 981/2014.
} 
El principio de confianza es un criterio muy importante para la armónica vida en sociedad y para la "división de trabajo" (en sentido amplio). Podría sintetizarse diciendo que no forma parte necesaria del rol social de cada individuo controlar todo el tiempo a los demás en el desarrollo de sus actividades; existe una "razonable creencia" de que cada uno cumplirá su rol debidamente ${ }^{67}$. Es un principio rector, de toda la teoría, por ello aparece (no siempre explícitamente) como el reverso de otros, dando luces sobre el "reparto" de los riesgos creados. Debe decirse que el uso poco cuidado de ciertos términos, aunque genera cierta confusión, el TS resuelve la problemática causal, en general, acertadamente. Además, la tendencia a utilizar indistintamente términos asociados a visiones iusfilosóficas y teorías diversas tiende a disminuir ${ }^{68}$.

\section{Conclusión}

El extenso recorrido que se ha hecho a lo largo del presente, permite llegar a una serie de conclusiones relevantes. Lo primero que debe tenerse en cuenta es que, a excepción de algunos aspectos concretos, no es posible afirmar con certeza que la Sala Civil del Tribunal Supremo sigue una postura completamente definida sobre el modo de entender y determinar la causalidad.

No obstante la ausencia de claridad total a la que se hace referencia en el párrafo anterior, sí se puede proponer con cierto grado de fiabilidad una serie de líneas rectoras que guía el proceder del Tribunal Supremo.

El Tribunal Supremo sí ha dejado clara la exigencia de la determinación del nexo causal como requisito para la imputación de responsabilidad, cuya prueba incumbe siempre el actor (a lo menos en los extremos necesarios para establecer una presunción). Pero esa exigencia en materia de responsabilidad por daños se ha visto condicionada por la impronta subjetivista del artículo 1902 del Código Civil.

Para la determinación de dicho nexo, debe diferenciarse la causa física o material de la causa jurídica, que puede llamarse también i m p u t a c i ó n o b j e t i va (haciendo referencia a la imputación objetiva del resultado, claro está).

En lo que hace a la determinación de la causalidad jurídica, se ha hecho recurso de diferentes posturas a lo largo del tiempo. Primero ocupó un lugar casi exclusivo en la Sala Civil la teoría de la causalidad adecuada.

${ }^{67}$ Tribunal Supremo de España, de 5/11/2009, STS 7120/2009.

${ }^{68}$ El uso de los términos varía de un Juez Preopinante a otro, pero algunos han fallado con gran claridad en ciertas oportunidades (véase Tribunal Supremo de España, de 22/2/2010, STS 745/2010). 
Pero con el correr de los años, sin apartarse de ella, se fueron incorporando criterios de la teoría de la imputación objetiva según fuera desarrollada en Alemania, sobre todo por Roxin y Jakobs.

En la actualidad se aplica una teoría con caracteres propios en la que, posiblemente, ha tenido un papel importante el jurista español y actual miembro de la Sala Civil Fernando Pantaleón Prieto.

La teoría podría sintetizarse (recordando que la diversidad de criterios puede ser aparente) que la imputación objetiva es el nombre que se da al tramo jurídico objetivo de la atribución causal. De este modo, la teoría funciona como marco general. Además, ese tramo imputativo se realiza mediante la aplicación de una serie de criterios tomados de la llamada teoría de la imputación objetiva (principalmente según la han extendido Roxin y Jakobs) y "amalgamados" con elementos de la teoría de la causalidad adecuada, que funciona también como criterio rector y objetivo.

No existe de modo claro y uniforme una postura sobre el modo de darse tal "amalgama". Pero podría pensarse, de modo similar -no igual-a lo expuesto por Xiol Ríos, que la jurisprudencia pretende determinar cuál es la conducta adecuada al daño. Ese objetivo se alcanza aplicando los criterios de la imputación objetiva (dentro de los cuales se encontraría el criterio de adecuación de la conducta al daño, como uno más). Es necesaria una última aclaración: no toda influencia de la causalidad adecuada sobre la imputación objetiva se resuelve felizmente, la razón principal, se cree, es la tendencia a la subjetividad propia de la causalidad adecuada (que se agrava en este caso por la normativa española).

Por nuestra parte, entendemos que la causalidad adecuada es en parte fáctica y en parte jurídica, y el sentido común (sentido jurídico, podríamos decir) ayudado por los criterios de la imputación objetiva deben tender a determinar aquella causa adecuada (como criterio rector y objetivo del análisis del iter causal). Pero la compatibilidad de estas dos corrientes (causalidad adecuada e imputación objetiva) debe resolverse con una tendencia a la objetividad (no a la subjetividad, que es lo que hace la Sala Civil del TS), de otro modo puede generar disparidad de ideas y, a la larga o a la corta, injusticias.

En definitiva, a medida que pasan los años se vierte más luz sobre el asunto, y se espera que tal claridad siga su curso creciente. Conviene que disminuya la diversidad en el uso de ciertos criterios y el uso indistinto de ciertos términos que en el ámbito jurídico han significados cosas diversas; así como resulta conveniente que continúen los intentos por desligar el tramo causal de la imputación subjetiva. 


\section{BiBLIOGRAFíA}

Díez-Picazo, Luis, Derecho de daños (Madrid, Civitas, 1999).

Fernández Crende, Antonio, Imputación objetiva en un caso de responsabilidad civil ex delicto: criterio de la provocación. Comentario a la STS, 2a 26.9.2005, en InDret 1 (2006), pp. 1-9.

Fierro, Guillermo Julio, Causalidad e imputación: caso fortuito, imputación objetiva, tentativa, delito de omisión, culposos y preterintencionales, causalidad cientifica, delito imposible (Buenos Aires, Astrea, 2002).

GOLDENBERG, Isidoro, La relación de causalidad en la responsabilidad civil (Buenos Aires, Editorial Astrea, 1984).

JaKoBs, Günther, La imputación objetiva en el Derecho Penal (Buenos Aires, Ad Hoc, 1996).

Jiménez de AsúA, Luis, Tratado de derecho penal (Buenos Aires, Losada, 1951).

Larenz, Karl, Derecho de obligaciones (Madrid, Revista de Derecho Privado, 1958).

López Mesa, Marcelo, El mito de la causalidad adecuada, en La Ley 28.2 (2008), pp. $1-5$.

Mazeaud, Henry - Mazeaud, Jean, Lecciones de derecho civil (Buenos Aires, Ediciones Jurídicas Europa-America, 1978).

Mir PUig, Santiago, Significado y alcance de la imputación penal, en Revista Electrónica de Ciencia Penal y Criminología 05-05 (2003) 05-1 a 05-10.

Pantaleón, Fernando, Causalidad e imputación objetiva: Criterios de imputación, en Asociación de Profesores de Derecho Civil (ed.), Centenario del Código Civil (1889-1989) (Madrid, Centro de Estudios Ramón Areces, 1990), pp. 1561-1591.

Reglero Campos, Luis Fernando - Medina Alcoz, Luis, El nexo causal. La pérdida de oportunidad. Las causas de eximición de responsabilidad: culpa de la víctima y fuerza mayor, en Reglero Campos, Luis Fernando y Busto Lago, José Manuel. (eds.), Tratado de responsabilidad civil (5a ed., Navarra, Aranzadi, 2014) pp. 767-900.

Roca Trías, Encarna, El riesgo como criterio de imputación subjetiva del daño en la jurisprudencia del Tribunal Supremo, en InDret 4 (2009), pp. 1 - 17.

Rojas Aguirre, Luis Emilio, Lo subjetivo en el juicio de imputación objetiva: ¿Aporía teórica?, en Revista de Derecho (Universidad Austral de Chile) XXIII (2010), pp. 233-54.

Roxin, Claus, Problemas de la imputación objetiva, en Revista de Derecho Penal [ed. Depalma] No 2 (2001) pp. 12-35.

Roxin, Claus, Derecho penal: parte general. 1. Fundamentos, la estructura de la teoría del delito (traducido por Luzón Peña, Diego. Manuel, Díaz y García Conlledo, Miguel y Vicente Remesal, Javier DE, Madrid, Civitas, 2008).

Salvador Coderch, P. y Fernández Crende, Antonio, Causalidad y responsabilidad. Tercera edición», InDret 1 (2006), pp. 1-40.

Trigo Represas, Félix, Los presupuestos de la responsabilidad civil, en Responsabilidad Civil y Seguros (2004), pp. 245-53.

XIol Ríos, Juan Antonio, La imputación objetiva en la jurisprudencia reciente del Tribunal Supremo, La Ley - Actualidad Civil 2 (2010), pp. 123-49.

Zaffaroni, Eugenio Raúl, Tratado de Derecho Penal. Parte general, III, (Buenos Aires, Ediar, 1981).

Zaffaroni, Eugenio Raúl - Alagia, Alejandro - Slokar, Alejandro, Derecho penal: parte general (2a ed., Buenos Aires, Ediar, 2005). 


\section{Jurisprudencia citada del Tribunal Supremo de España}

Sala Primera (Civil), de 18/03/2014, José Antonio Seijas Quintana, STS 981/2014. Sala Primera (Civil), de 04/10/2012, José Antonio Seijas Quintana, STS 6203/2012. Sala Primera (Civil), de 11/06/2012, José Antonio Seijas Quintana, STS 3955/2012. Sala Primera (Civil), de 27/02/2012, José Antonio Seijas Quintana, STS 1578/2012. Sala Primera (Civil), de 06/02/2012, Juan Antonio Xiol Ríos, STS 1581/2012.

Sala Primera (Civil), de 31/01/2012, José Antonio Seijas Quintana, STS 274/2012. Sala Primera (Civil), de 20/12/2011, Francisco Marín Castán, STS 9152/2011. Sala Primera (Civil), de 15/12/2010, José Ramón Ferrándiz Gabriel, STS 7726/2010. Sala Primera (Civil), de 25/11/2010, Encarnación Roca Trías, STS 6381/2010. Sala Primera (Civil), de 22/2/2010, José Antonio Seijas Quintana, STS 745/2010. Sala Primera (Civil), de 5/11/2009, Francisco Marín Castán, STS 7120/2009. Sala Primera (Civil), de 30/06/2009, Encarnación Roca Trías, STS 4450/2009. Sala Primera (Civil), de 23/04/2009, Encarnación Roca Trías, STS 2215/2009. Sala Primera (Civil), de 04/03/2009, José Antonio Seijas Quintana, STS 919/2009. Sala Primera (Civil), de 19/02/2009, José Antonio Seijas Quintana, STS 461/2009. Sala Primera (Civil), de 24/11/2008, Encarna Roca Trías, STS 6277/2008.

Sala Primera (Civil), de 19/11/2008, Ignacio Sierra Gil de la Cuesta, STS 5993/2008. Sala Primera (Civil), de 15/07/2008, Joaquín Samper Juan, STS 1839/2008.

Sala Primera (Civil), de 30/7/2008, Juan Antonio Xiol Ríos, STS 4766/2008. Sala Primera (Civil), de 14/3/2008, Vicente Luis Montes Penades, STS 4329/2008. Sala Primera (Civil), de 20/12/2007, Ignacio Sierra Gil De La Cuesta, STS 8265/2007. Sala Primera (Civil), de 17/05/2007, Pedro José Yagüe Gil, STS 545/2007.

Sala Primera (Civil), de 17/04/2007, Vicente Luís Montes Penades, STS 2561/2007. Sala Primera (Civil), de 07/06/2006, Francisco Monterde Ferrer, STS 619/2006. Sala Primera (Civil), de 29/04/2006, Juan Antonio Xiol Ríos, STS 2172/2006. Sala Primera (Civil), de 2/3/2006, Juan Antonio Xiol Ríos, STS 1469/2006. Sala Primera (Civil), de 14/02/2006, José Antonio Seijas Quintana, STS 836/2006. Sala Primera (Civil), de 21/10/2005, Juan Saavedra Ruiz, STS 758/2005.

Sala Segunda (Penal), de 26/9/2005, Juan Ramón Berdugo Gómez de la Torre, STS $5537 / 2005$.

Sala Primera (Civil), de 24/10/2003, José de Asís Garrote, STS 6556/2003.

Sala Primera (Civil), de 17/7/2003, Antonio Gullón Ballesteros, STS 5108/2003. Sala Primera (Civil), de 13/12/2002, Jesús Eugenio Corbal Fernández, STS 8399/2002. Sala Primera (Civil), de 22/07/2002, Jesús Eugenio Corbal Fernández, STS 5568/2002. Sala Primera (Civil), de 30/6/2000, Jesús Eugenio Corbal Fernández, STS 5348/2000. Sala Primera (Civil), de 01/04/1997, Pedro González Poveda, STS 2312/1997. Sala Segunda (Penal), de 5/4/1983, José Manual Ramírez, STS 1583/1983. Sala Segunda (Penal), de 20/5/1981, José Moyna Ménguez, STS 4507/1981. Sala Primera (Civil), de 21/01/1957, Juan Serrada Hernández, STS 188/1957. 
